\title{
An outbreak of post cataract Pseudomonas aeruginosa acute endophthalmitis in Egypt
}

Amal Abo Elnour ${ }^{1 *}$, Sahar Negm², Ahmed Ismail ${ }^{3}$ and Mostafa A. Elhusseiny ${ }^{3}$

\begin{abstract}
Background: Outbreaks of post-cataract surgery endophthalmitis are often due to infection with Gram-negative organisms including Pseudomonas aeruginosa, which usually has poor visual prognosis due to its virulence factors and intrinsic resistance to antimicrobial agents.

This work was concerned with investigation of outbreak of post phacoemulsification surgeries that took place at an eye care center, at 1-day period in Egypt. Retrospective case series study had been carried out with participants of six patients who underwent phacoemulsification surgeries. The clinical settings and treatment outcomes were described.

Results: The results showed isolation of Pseudomonas aeruginosa, multidrug-resistant strain in all cases; five vitreous samples and one anterior chamber fluid sample. No evisceration or enucleation had to be done to any of these eyes in 8-month follow-up period. The source of outbreak was most probably the reused-reprocessed cassette of the phacoemulsifier machine. No pseudomonas strains could be isolated from other environmental samples.

Conclusion: Early diagnosis and prompt recall of suspected cases and applying outbreak control measures helped to achieve good visual and anatomic outcomes. Reprocessing and reuse of single use devices should not be done, except after following the international regulations and the manufacturers' information on the appropriate decontamination process to allow reuse, including cleaning, disinfection, and method of sterilization.
\end{abstract}

Keywords: Phaco-machine, Equipment contamination, Clinical findings, Antibiotics

\section{Background}

Acute postoperative endophthalmitis refers to infectious endophthalmitis present shortly after ocular surgery. It is a serious complication of cataract and intraocular lens (IOL) implantation surgery that present within 1-2 weeks, usually $3-5$ days after the surgery (Durand 2017). The incidence ranges from 0.07 to $0.12 \%$ (Kresloff et al. 1998; Schmier et al. 2016). Bacteria are the most common infecting agents. The causative organisms represent bacteria from patient's own periocular flora, of which the most common is Staphylococcus epidermidis: 60 to $80 \%$ of cases (Durand 2017; Kresloff et al. 1998; Pijl et al. 2010). However, outbreaks of post-cataract surgery endophthalmitis are often due to infection with Gram-negative organisms including Pseudomonas aeruginosa (Guerra et al. 2012).

\footnotetext{
* Correspondence: amalaboelnour@gmail.com

${ }^{1}$ Microbiology and Immunology Unit, Department of Microbiology and Parasitology, Research Institute of Ophthalmology (RIO), 2 El Ahram Street, Giza 12611, Egypt

Full list of author information is available at the end of the article
}

Pseudomonas aeruginosa is saprophytic Gram-negative bacteria, widely distributed in water, soil, and plants. $P$. aeruginosa is an important etiologic pathogen in health care-associated infections (HAI) and are responsible for $13 \%$ of infections of the eye, the nose, the ear, and the throat. Outbreaks of postoperative endophthalmitis caused by $P$. aeruginosa have been detected in previous studies (Pathengay et al. 2012; Hoffmann et al. 2002; Mateos et al. 2006; Pinna et al. 2010). P. aeruginosa has intrinsic resistance which renders it resistant to second-generation penicillins, tetracycline, chlorampheni$\mathrm{col}$, and narrow-spectrum and expanded-spectrum cephalosporins. Virulence factors, extracellular products including proteases, and the ability to produce biofilm may explain the poor visual prognosis in Pseudomonas aeruginosa endophthalmitis despite rapid antibiotic therapy (Guerra et al. 2012). Microbial contaminations may occur through direct transmission of pathogen by contaminated hands or by indirect transmission via other inanimate objects that keep acting as a reservoir of pathogen in 
dirty environment (Saeed and Rasheed 2011). The association with intrinsic contamination of ophthalmic solutions and contaminated instruments or equipment, like contaminated phaco-emulsification machines, was demonstrated in previous works (Hoffmann et al. 2002; Mateos et al. 2006; Pinna et al. 2010; Sunenshine et al. 2009a; Boks et al. 2006). Other less possible causes of infection included ventilation systems and defective sterilization, or sometimes, no possible source could be identified (Guerra et al. 2012; Pathengay et al. 2012).

The spectrum of bacterial sensitivity to antibiotics in ocular infections is continuously changing, with more and more emergence of microbial resistance leading to difficult empirical choice of antibiotic therapy (Mahran et al. 2014; Kuznar 2017). The aim of this work was to investigate the etiology of endophthalmitis outbreak after phacoemulsification surgeries, which took place at an ophthalmology center in Egypt. We discussed the Clinical picture, the treatment plan, and the final visual outcome.

\section{Methods}

Medical records were reviewed of six patients with acute postoperative endophthalmitis after phacoemulsification surgery at ophthalmology center, Giza city, Egypt, 1-day period, August 11, 2015. For all patients, the following data were collected: demographic data (age and gender), the affected eye, anesthesia type, kind of surgery and type of implanted IOL, location where the surgery took place, presenting signs and symptoms, time between phaco-emulsification surgery and diagnosis of endophthalmitis, sampling site for culture, antibiotic sensitivity test result, treatment schedule, and outcome. Treatment of endophthalmitis cases started promptly on the day of diagnosis for all patients. As soon as the first case of post phacoemulsification endophthalmitis was diagnosed, the rest of patients operated on that day were recalled for clinical examination and investigation. The patients underwent fortified antibiotic eye drops, anterior chamber irrigation, and administration of intravitreous antibiotics. Three cases underwent primary vitrectomy. Secondary vitrectomy (reoperation) was performed in cases with poor response to the given treatment in addition to reinjection of intravitreous antibiotics following the results of the antibiotic sensitivity tests.

After confirming outbreak diagnosis, all the operating rooms were closed, air sampling for microbial air count was done, thorough cleaning and air fumigation with $\mathrm{H}_{2} \mathrm{O}_{2}$ disinfectant were performed, the air-conditioning system was cleaned and reconditioned, the tubes of phaco-machine were changed, and a new cassette was used. The sterilization procedures for reprocessing all instruments had been accessed and sterilization indicators were checked. After these procedures, no other cases of acute endophthalmitis were reported, indicating ending of the outbreak.

\section{Microbiologic studies}

Vitreous aspirates (approx. $0.1-0.3 \mathrm{~mL}$ of vitreous) were collected in the operative room using sterile syringes before antibiotics were administered intravitreally. Aqueous sample was obtained at the limbus for A/C tap using 30-g needle attached to $\mathrm{TB}$ syringe to withdraw about $0.1 \mathrm{ml}$. Samples then were sent immediately to the microbiology laboratory (within the same hospital) and were subjected to complete microbial identification.

Bacterial cultures were prepared from five vitreous samples and one anterior chamber sample. The aspirated materials were first inoculated directly onto the solid media: nutrient agar, blood and chocolate agar, MacConkey's agar, and Sabouraud's dextrose agar. For direct test; the sample obtained was also used to make a direct smear onto clean sterile glass slides and it was Gram stained. The inoculated media were all incubated aerobically at $37^{\circ} \mathrm{C}$, examined daily. Chocolate agar plates were incubated in $\mathrm{CO} 2$ incubator to ensure $5-10 \% \mathrm{CO} 2$. Positive growth culture was followed by bacterial identification according to colony morphology, Gram staining, pigments, and biochemical reactions. Pseudomonas species was identified as Gram-negative bacilli, nonlactose fermenter which gave a positive oxidase reaction, and its culture showed green pigmentation and had fruity odor.

Antibiotic susceptibility to ceftazidime, chloramphenicol, neomycin, amikacin, gentamycin, tobramycin, aztreonam, ofloxacin, levofloxacin, moxifloxacin, sulfamethoxazol/trimethoprim, ampicillin/sulbactam, piperacillin/tazobactam, ceftazidime, cefepime, cefoperazone, cefuroxime, fucidene, cefotaxime, and polymixin B was tested using the classic agar diffusion (Kirby-Bauer) method (Hudzicki 2009). Standardized bacterial suspension for bacterial inoculation in antibiotic sensitivity test was prepared by adding $4-5$ isolated colonies to $5 \mathrm{ml}$ of (brain-heart infusion broth) to form a homogenous suspension, allowing to incubate at 37 ${ }^{\circ} \mathrm{C}$ until it is slightly visibly turbid (about $4 \mathrm{~h}$ ). The turbidity of the suspension was adjusted to the optical density of a $0.5 \mathrm{McF}$ arland tube $(0.14-0.15 \mathrm{~nm})$. The inoculum of each isolate was swabbed onto Mueller-Hinton agar using a sterile cotton swab done evenly over the whole surface of the agar plate to have a uniform bacterial growth. The discs of the antibiotics were applied to the plates with a suitable distance in-between (about $24 \mathrm{~mm}$ ). After that, within 15 min, the plates were incubated at $37^{\circ} \mathrm{C}$. The plates were inspected for inhibition zones after $24 \mathrm{~h}$ of incubation. The diameter of the complete inhibition zones was measured by a ruler.

Sensitivity pattern interpretation performed on Muller Hinton agar was done using the specific chart according 
to the Clinical and Laboratory Standards Institute (CLSI) guidelines (Wayne 2006). Furthermore, environmental samples were obtained from the air-conditioning system of the operating rooms, the betadine (povidone-iodine) solution, Visco gel used for applying the lens into the eye, local anesthetic drug vials and the irrigation solutions (Ringer's lactate, dextrose and saline) and air samples. All samples were used for microbiological culture test (Pinna et al. 2010). We were unlucky to obtain sample from the cassette of Phaco machine used in all phacoemulsification surgeries performed in August 11 at OT4, as the cassette was disposed of in the infectious waste bag before the next day.

\section{Results}

Six patients (one male and five females) had presented with acute endophthalmitis. Age range was 3-70 years (average 50 years). Endophthalmitis started 1-4 days after surgery (the median interval was 2 days) (Table 1). Four cases had visual acuity of Light perception at the time of diagnosis and two cases presented with no light perception (Table 2).

Multidrug-resistant MDR Pseudomonas isolates (defined as those isolates resistant to 3 or more classes of antibiotics) were found in five vitreous samples and one AC fluid. The antibiogram test showed that imepenem, meropenem, polymixin B, and Sulbactam/cefoperazone were the most active drugs against Pseudomonas aeruginosa followed by fluoroquinolones. All other antibiotics tested showed high resistance, including aminoglycosides, chloramphenicol, and cephalosporin (Table 3). No evisceration or enucleation had been applied to any of these eyes in a 3-month follow-up period. All endophthalmitis cases had their phacoemulsification surgery done in 1 day at the same operative room, using one phaco-machine (Table 1).

No pseudomonas were isolated from any environmental sample. The most likely source of outbreak was the reused-reprocessed cassette (external connecting tubes) of the phacoemulsifier instrument. The cassette was disposed of before the next day of surgery. Other types of ophthalmic surgeries were carried out in that OR in August 11 with no postoperative complaint.

\section{Discussion}

Postoperative endophthalmitis is a serious complication of cataract and intraocular lens implantation surgery; the incidence ranges from 0.07 to $0.12 \%$ (Kresloff et al. 1998). Many previous studies had reported outbreaks of post cataract surgery endophthalmitis caused by $P$. aeruginosa (Guerra et al. 2012; Pathengay et al. 2012; Hoffmann et al. 2002; Mateos et al. 2006; Pinna et al. 2010; Sunenshine et al. 2009a; Centers for Disease Control and Prevention (CDC) 1992; Sunenshine et al. 2009b; Ramappa et al. 2015; Kenchappa et al. 2009; Arsan et al. 1996). One of the Pseudomonas endophthalmitis outbreaks compromised large numbers of cases of 45 patients with 45 affected eyes in 2-day period (Guerra et al. 2012).This study included six eyes of six patients (six cultures positive for Pseudomonas) in 1-day period. Pseudomonas aeruginosa is a saprophytic Gram-negative bacterium that is widely distributed in water, soil, and plants. $P$. aeruginosa is an important opportunistic pathogen in health care-associated infections (HAI) (Hoffmann et al. 2002). The $P$. aeruginosa epidemics seem to be related to contaminated intraocular irrigating solutions (Guerra et al. 2012; Mateos et al. 2006), lens solution (Ramappa et al. 2015), and trypan blue dye (Mateos et al. 2006; Sunenshine et al. 2009a), in povidone-iodine solution (Pinna et al. 2010), at the phacoemulsifier fluid circulation (Pathengay et al. 2012; Hoffmann et al. 2002; Pinna et al. 2010; Eifrig et al. 2003; Cruciani et al. 1998; Zaluski et al. 1999) and air-conditioning units (Boks et al. 2006). In this study, we could not identify the exact source of the outbreak as all the screened environmental samples gave negative results. However, the reused reprocessed cassette of the phaco-machine was used in common for all cases of phacoemulsification performed that day in operative room OT4. The cassette was disposed of in the infectious bag before the

Table 1 Clinical and demographic data of patients with post-phacoemulsification endophthalmitis

\begin{tabular}{|c|c|c|c|c|c|c|c|}
\hline $\begin{array}{l}\text { Patient } \\
\text { no. }\end{array}$ & $\begin{array}{l}\text { Age (years)/ } \\
\text { gender }\end{array}$ & Eye & $\begin{array}{l}\text { Type of } \\
\text { anesth. }\end{array}$ & Surg. type and IOL material & $\begin{array}{l}\text { Place of } \\
\text { surg. }\end{array}$ & $\begin{array}{l}\text { Days till endoph. } \\
\text { diagnosis }\end{array}$ & $\begin{array}{l}\text { Culture } \\
\text { site }\end{array}$ \\
\hline 1 & $45 / F$ & RE & Local & SICS+IOL (Acriva UD 613) & OT-4 & 1 & Vitreous \\
\hline 2 & $50 / F$ & LE & Local & SICS+ IOL (Acriva UD613) & OT-4 & 1 & Vitreous \\
\hline 3 & $65 / F$ & RE & Local & SICS+ IOL (Acriva UD613) & OT-4 & 4 & Vitreous \\
\hline 4 & $70 / F$ & RE & Local & SICS+ IOL (Acriva UD613) & OT-4 & 4 & Vitreous \\
\hline 5 & $3 / F$ & LE & General & $\begin{array}{l}\text { SICS + Artisan Aphakia OPHTEC } \\
\text { IOL implantation }\end{array}$ & OT-4 & 2 & AC fluid \\
\hline 6 & $70 / M$ & LE & Local & SICS+ IOL (Acriva UD613) & OT-4 & 4 & Vitreous \\
\hline
\end{tabular}

LE left eye, IOL intraocular lens, OT operating theater, (Acriva UD613) 2-oxiethyl-methacrylate 2-hydroxymethacrylate, RE right eye, SICS small incision cataract surgery. 
Table 2 Summary of clinical findings and treatment in 6 patients with post-phacoemulsification endophthalmitis

\begin{tabular}{|c|c|c|c|c|c|}
\hline $\begin{array}{l}\text { Patient } \\
\text { no. }\end{array}$ & VA & Clinical signs & $\begin{array}{l}\text { Therapy before culture and } \\
\text { sensitivity }\end{array}$ & Therapy after culture and sensitivity & Outcome \\
\hline 1 & $\begin{array}{l}\text { No } \\
\text { LP }\end{array}$ & $\begin{array}{l}\text { Eyelid edema, conjunctival } \\
\text { congestion, corneal edema, } \\
\text { exudates in AC, 2-mm hypopyon, } \\
\text { ciliary injection hypopyon, and } \\
\text { increase IOP }\end{array}$ & $\begin{array}{l}\text { Intravitreal antibiotic injection + } \\
\text { fortum, vancomycin, amikacin ED/h } \\
+ \text { cefobid } 1 \mathrm{~g} \mathrm{IM} / \text { day for } 3 \text { days }+ \\
\text { augmentine } 1 \mathrm{~g} \text { oral } / 12 \mathrm{~h}+\text { flagyl } \\
500 \mathrm{mg} / 12 \mathrm{~h}+\text { combigan ED } 2 \mathrm{td}+ \\
\text { cycloplegic ED 3td }\end{array}$ & $\begin{array}{l}\text { Intravitreal antibiotic injection + } \\
\text { Tienam } 50 \mathrm{mg} 3 \mathrm{td} \text { IV }+ \text { Amikacin } \\
\text { fortified ED/h + vegamoxED/2 } \mathrm{h}+ \\
\text { pred forte ED } 6 \mathrm{td}+\text { cycloplegic and } \\
\text { combigan ED } 3 \mathrm{td}+\text { cataflam } / 12 \mathrm{~h}+ \\
\text { zantak } 150 \mathrm{mg} / 12 \mathrm{~h}\end{array}$ & $L P$ \\
\hline 2 & $L P$ & $\begin{array}{l}\text { Eyelid edema, conjunctival } \\
\text { congestion, corneal edema, } \\
\text { exudates in AC, and increase IOP }\end{array}$ & $\begin{array}{l}\text { Intravitreal antibiotic injection + } \\
\text { fortum, vancomycin, amikacin ED/h } \\
+ \text { cefobid } 1 \mathrm{~g} \mathrm{IM} / \text { day for } 3 \text { days }+ \\
\text { augmentine } 1 \mathrm{~g} \text { oral } / 12 \mathrm{~h}+\text { flagyl } \\
500 \mathrm{mg} / 12 \mathrm{~h}+\text { combiganED } 2 \mathrm{td}+ \\
\text { cycloplegic ED } 3 \mathrm{td}\end{array}$ & $\begin{array}{l}\text { Intravitreal antibiotic injection+ } \\
\text { Tienam } 50 \mathrm{mg} 3 \mathrm{td} \text { IV }+ \text { Amikacin } \\
\text { fortified ED/h + vegamoxED/2 } \mathrm{h}+ \\
\text { pred forte ED } 6 \mathrm{td}+\text { cycloplegic and } \\
\text { combigan ED } 3 \mathrm{td}+\text { cataflam } / 12 \mathrm{~h}+ \\
\text { zantak } 150 \mathrm{mg} / 12 \mathrm{~h}\end{array}$ & LP \\
\hline 3 & $L P$ & $\begin{array}{l}\text { Eyelid edema, conjunctival } \\
\text { congestion, corneal edema and } \\
\text { infiltration. AC exudates. }\end{array}$ & $\begin{array}{l}\text { Intravitreal antibiotic injection + } \\
\text { fortum, vancomycin, amikacin ED /h } \\
+ \text { cefobid } 1 \mathrm{~g} \mathrm{IM/day} \mathrm{for} 3 \text { days }+ \\
\text { augmentine } 1 \mathrm{~g} \text { oral/12 } \mathrm{h}+\text { flagyl } \\
500 \mathrm{mg} / 12 \mathrm{~h}+\mathrm{combiganED} 2 \mathrm{td}+ \\
\text { cycloplegic ED } 3 \mathrm{td}\end{array}$ & $\begin{array}{l}\text { Intravitreal antibiotic injection+ } \\
\text { Tienam } 50 \mathrm{mg} 3 \mathrm{td} \text { IV }+ \text { Amikacin } \\
\text { fortified ED/h }+ \text { vegamoxED/2 } \mathrm{h}+ \\
\text { pred forte ED } 6 \mathrm{td}+\text { cycloplegic and } \\
\text { combigan ED } 3 \mathrm{td}+\text { Oflox.ED } 1 \times 5+ \\
\text { cataflam } / 12 \mathrm{~h}+\text { zantak } 150 \mathrm{mg} / 12 \mathrm{~h}\end{array}$ & LP \\
\hline 4 & $L P$ & $\begin{array}{l}\text { Eyelid edema, conjunctival } \\
\text { congestion, corneal edema, } \\
\text { exudates in AC. }\end{array}$ & $\begin{array}{l}\text { Intravitreal antibiotic injection + } \\
\text { fortum, vancomycin, amikacin ED } / \mathrm{h} \\
+ \text { cefobid } 1 \mathrm{~g} \mathrm{IM} / \mathrm{day} \text { for } 3 \text { days }+ \\
\text { augmentine } 1 \mathrm{~g} \text { oral } / 12 \mathrm{~h}+ \\
\text { flagyl500mg } / 12 \mathrm{~h}+\text { combiganED } 2 \mathrm{td} \\
+ \text { cycloplegic ED } 3 \mathrm{td}\end{array}$ & $\begin{array}{l}\text { Intravitreal antibiotic injection+ } \\
\text { Tienam } 50 \mathrm{mg} 3 \mathrm{td} \text { IV }+ \text { Amikacin } \\
\text { fortified ED/h + vegamoxED/2 } \mathrm{h}+ \\
\text { pred forte ED } 6 \mathrm{td}+\text { cycloplegic and } \\
\text { combigan ED } 3 \mathrm{td}+\text { cataflam } / 12 \mathrm{~h}+ \\
\text { zantak } 150 \mathrm{mg} / 12 \mathrm{~h}\end{array}$ & LP \\
\hline 5 & $L P$ & $\begin{array}{l}\text { Conjunctival congestion, } \\
\text { Chemosis, corneal edema, } \\
\text { exudates in AC. }\end{array}$ & $\begin{array}{l}\text { Ac wash with vancomycin, fortum, } \\
\text { Vancomycin, Amikacin ED } / \mathrm{h}+ \\
\text { cefobid1g IM } / \text { day for } 3 \text { days }+ \\
\text { augmentine } 1 \mathrm{~g} \text { oral } / 12 \mathrm{~h}+\text { flagyl } \\
500 \mathrm{mg} / 12 \mathrm{~h}+\text { combiganED } 2 \mathrm{td}+ \\
\text { cycloplegic ED } 3 \mathrm{td}\end{array}$ & As above + oflox.ED 5 td & $\begin{array}{l}\text { Marked } \\
\text { improvement, yet an } \\
\text { amblyopic eye needs } \\
\text { prolonged follow up } \\
\text { to access VA }\end{array}$ \\
\hline 6 & LP & $\begin{array}{l}\text { Eyelid edema, discharge, } \\
\text { conjunctival congestion, corneal } \\
\text { edema, exudates in AC. }\end{array}$ & $\begin{array}{l}\text { Ac wash with vancomycin, fortum, } \\
\text { Vancomycin, Amikacin ED } / \mathrm{h}+ \\
\text { cefobid1g IM /day for } 3 \text { days }+ \\
\text { augmentine } 1 \mathrm{~g} \text { oral/12 } \mathrm{h}+\text { flagyl } \\
500 \mathrm{mg} / 12 \mathrm{~h}+\text { combiganED } 2 \mathrm{td}+ \\
\text { cycloplegic ED } 3 \mathrm{td}\end{array}$ & $\begin{array}{l}\text { Intravitreal antibiotic injection+ } \\
\text { Tienam } 50 \mathrm{mg} 3 \mathrm{td} \text { IV }+ \text { amikacin } \\
\text { fortified ED/h + vegamox ED/2 } \mathrm{h}+ \\
\text { pred forte ED } 6 \mathrm{td}+\text { cycloplegic and } \\
\text { combigan ED } 3 \mathrm{td}+\text { cataflam } / 12 \mathrm{~h}+ \\
\text { zantak } 150 \mathrm{mg} / 12 \mathrm{~h}\end{array}$ & $\mathrm{HM}$ \\
\hline
\end{tabular}

$A C$ anterior chamber, 2td twice daily, HM hand motion, IOL intraocular lens, $L P$ light perception, 3td three times daily, VA visual acuity, ED eye drops, IM intramuscular, $I V$ intravenous, $V A$ visual acuity

next day of operative surgery; no sample could be obtained for pathogen isolation.

Single-use items must be discarded after single use only or reprocessed using validated methods following instructions of FDA regulations (Grohmann 2018), or national regulations because of the following: cleaning and decontamination become inadequate with reuse of instrument. This can be due to instrument construction (e.g., small bore), or surface damage occurring, preventing removal of all debris or organisms. Component materials of the instrument may be damaged, leading to the risk of falling of fragments into the eye during the operation. Some materials can adsorb or absorb certain chemicals, potentially causing harm (Grohmann 2018).

Before disconnecting the hand piece from the unit of phacoemulsification machine, the hand piece's ports, tips, and tubing should be flushed. By flushing the hand piece, we can prevent build-up of material (which is difficult to remove) by cleaning inside the hand piece, thus preventing its occlusion. If the tips of hand pieces become occluded, several centers consider that a potential cause of toxic anterior segment syndrome (TASS) (Swaddiwudhipong et al. 1995). Many bacterial species including Pseudomonas species have the ability to form biofilms in different environments as a defense against predation. A biofilm comprises microorganisms multicellular communities in which cells stick to each other and also to a surface. These cells are embedded in an extracellular slimy matrix. The biofilm bacteria are sheltered from harmful factors in the environment, such as antibiotics, and a host body's immune system. Biofilms may form on living or non-living surfaces, such as implants and tubing. Biofilm formation is an obstacle concerning the uses and design of ocular devices, such as contact lenses, conjunctival plugs, intraocular lenses, scleral buckles, lacrimal intubation devices, phacoemulsifier internal tubing, and orbital implants (Bispo et al. 2015). 
Table 3 Antibiogram test of Pseudomonas isolates: 6 eyes with postoperative endophthalmitis

\begin{tabular}{|c|c|c|c|c|c|c|}
\hline \multirow[t]{2}{*}{ Antibiotic tested } & \multicolumn{6}{|c|}{ Patient no. } \\
\hline & 1 & 2 & 3 & 4 & 5 & 6 \\
\hline Ofloxacin & $S$ & $S$ & $\mathrm{~S}$ & $S$ & I & $\bar{R}$ \\
\hline Levofloxacin & S & S & S & S & $S$ & I \\
\hline Moxifloxacin & S & S & $\mathrm{S}$ & S & $\mathrm{S}$ & $\mathrm{S}$ \\
\hline Amikacin & । & $\mathrm{R}$ & $\mathrm{R}$ & $\mathrm{R}$ & $\mathrm{R}$ & I \\
\hline Gentamycin & । & $\mathrm{R}$ & $\mathrm{R}$ & $\mathrm{R}$ & $\mathrm{R}$ & $\mathrm{R}$ \\
\hline Tobramycin & $\mathrm{R}$ & $\mathrm{R}$ & $\mathrm{R}$ & $\mathrm{R}$ & $\mathrm{R}$ & $\mathrm{R}$ \\
\hline Aztreonam & $\mathrm{R}$ & $\mathrm{R}$ & $\mathrm{R}$ & $\mathrm{R}$ & $\mathrm{R}$ & I \\
\hline Ampicillin/sulbactam & $\mathrm{R}$ & $\mathrm{R}$ & $\mathrm{R}$ & $\mathrm{R}$ & $\mathrm{R}$ & $\mathrm{R}$ \\
\hline Piperacillin/tazobactam (meropenem) & S & S & S & $\mathrm{S}$ & $\mathrm{S}$ & $\mathrm{S}$ \\
\hline Imepenem & $S$ & S & $S$ & $S$ & $\mathrm{~S}$ & $\mathrm{~S}$ \\
\hline Polymixin B & S & S & S & $\mathrm{S}$ & $\mathrm{S}$ & $\mathrm{S}$ \\
\hline Ceftazidime & $\mathrm{R}$ & $\mathrm{R}$ & $\mathrm{R}$ & $\mathrm{R}$ & $\mathrm{R}$ & I \\
\hline Cefepime & $\mathrm{R}$ & $\mathrm{R}$ & $\mathrm{R}$ & $\mathrm{R}$ & $\mathrm{R}$ & I \\
\hline Cefoperazone & $\mathrm{R}$ & $\mathrm{R}$ & $\mathrm{R}$ & $\mathrm{R}$ & $\mathrm{R}$ & I \\
\hline Sulbactam/cefoperazone & $\mathrm{S}$ & $\mathrm{S}$ & $\mathrm{S}$ & $\mathrm{S}$ & $\mathrm{S}$ & $\mathrm{S}$ \\
\hline Cefuroxime & $\mathrm{R}$ & $\mathrm{R}$ & $\mathrm{R}$ & $\mathrm{R}$ & $\mathrm{R}$ & $\mathrm{R}$ \\
\hline Fucidine & $\mathrm{R}$ & $\mathrm{R}$ & $\mathrm{R}$ & $\mathrm{R}$ & $\mathrm{R}$ & $\mathrm{R}$ \\
\hline Chloramphenicol & $\mathrm{R}$ & R & $\mathrm{R}$ & $\mathrm{R}$ & $\mathrm{R}$ & $\mathrm{R}$ \\
\hline Cefotaxime & $\mathrm{R}$ & $\mathrm{R}$ & $\mathrm{R}$ & $\mathrm{R}$ & $\mathrm{R}$ & $\mathrm{R}$ \\
\hline Trimethoprim/sulfamethoxazol & $\mathrm{R}$ & $\mathrm{R}$ & $\mathrm{R}$ & $\mathrm{R}$ & $\mathrm{R}$ & $\mathrm{R}$ \\
\hline
\end{tabular}

$I$ intermediate susceptibility, $R$ resistant, $S$ susceptible

Since improper reprocessing of surgical instruments is a major cause in postoperative endophthalmitis, it will be beneficial to follow the recommendations of Ophthalmic Surgery Centers regarding sterilization practices (Sebrell 2009; Graybill-D'Ercole 2013) which include the following: avoid using the antiquated term, "flash sterilization." Cleaning and rinsing instruments is an important step in their reprocessing after its use. Manufacturer's instructions must be followed starting from cleaning, disinfection, and for type and time of sterilization of instrument. Guard against recontamination while transporting and storing sterile instruments. A written policy should be in the place to ensure implementation of the proper procedures.

Primary vitrectomy is the recommended treatment for acute endophthalmitis patients with light perception according to the Endophthalmitis Vitrectomy Study (EVS). Better visual acuity should have antibiotic injection intravitreal, after withdrawing intraocular fluid sample for microbial culture (Endophthalmitis Vitrectomy Study Group EVSG 1995). Chen et al. (2011) suggested that vitrectomy (primary or secondary) reduces the likelihood of evisceration, In our study, three patients were submitted to primary vitrectomy, five of cases were re-operated upon and received injection of antibiotic intravitreally, and no patient underwent evisceration or enucleation in a 3-month follow-up. The severity of clinical aspect at the presentation of endophthalmitis was important for choosing the treatment performed. Generally, there is poor visual prognosis despite the intravitreal antibiotics treatment even in cases with sensitive microbial isolates (Pinna et al. 2010). In a previous literature, describing $P$. aeruginosa outbreak of post-cataract endophthalmitis, the outcome was evisceration or phthisis in $10(50 \%)$ of 20 eyes, and only 5 eyes had minimum degree of improvement (Pinna et al. 2010). In another study by Eifrig et al.; 18 (64\%) of 28 eyes with $P$. aeruginosa endophthalmitis underwent either enucleation or evisceration and none of the 9 patients with post-cataract endophthalmitis reached a final visual acuity of $5 / 200$ or better (Eifrig et al. 2003).

In our study, six patients reported outcome, three of them reached final acuity of light perception, two with hand movement and one patient with amblyopic eye showed marked improvement in signs but needs more time to improve visual acuity due to amblyopia. None of these eyes underwent evisceration.

The good visual outcome in some of these cases could be due to the prompt recall of patients as soon as diagnosis of endophthalmitis was reached and the treatment was given (anterior chamber irrigation, primary vitrectomy, and intravitreal antibiotics).

At the first moment, broad spectrum antibiotics for injection were chosen to cover Gram-positive and Gram-negative bacteria before microbial culture results. The safety and effectiveness of vancomycin and ceftazidime combined has been reported in experimental studies using mice and confirmed in human case series (Endophthalmitis Vitrectomy Study Group EVSG 1995; Yoshizumi et al. 1999).

$P$. aeruginosa has intrinsic resistance which explains its resistant to second-generation penicillins, tetracycline, chloramphenicol, and narrow-spectrum and expanded-spectrum cephalosporin. Antibiotic-resistant isolates of Pseudomonas show increasing prevalence (Kuznar 2017).

Multidrug-resistant $P$. aeruginosa is defined as those strains resistant to 3 or more classes of antibiotics including: penicillins (piperacillin, ticarcillin, and piperacillin-tazobactam), cephalosporins (ceftazidime and cefepime), monobactams, aminoglycosides, and fluoroquinolone antibiotics (Pinna et al. 2010).

In our study, resistance to cefotaxime, ceftazidime, cefoperazone, cefuroxime, Cefepime, aztreonam, ampicillin-sulbactam, gentamycin, tobramycin, amikacin, fucidene, and trimethoprim-sulfamethoxazol was observed. The other antibiotics tested (imepenem, meropenem, piperacillin-tazobactam, polymixin B, levofloxacin, 
ofloxacin, and moxifloxacin) were effective on the isolated Pseudomonas. This result, except sensitivity to amikacin was consistent with the one reported by Gad et al. (2007). However, another study by (Falavarjani et al. 2017) showed similar results; sensitivity to ciprofloxacin and imipenem $100 \%$ but more sensitivity pattern to cephalosporin (ceftazidime in $83.4 \%$ ) and aminoglycosides (amikacin in 88.3\%). This discrepancy can be explained by the fact that antibiotic-resistant isolates of Pseudomonas show increasing prevalence in different parts of the world (Kuznar 2017).

\section{Conclusions}

In the present study, the source of the post phacoemulsification endophthalmitis outbreak was likely to be the cassette of the phaco-machine. Implementation of infection prevention and control policies in cleaning, disinfection, and sterilization of surgical instruments is a must. Single use medical devices should not be reprocessed or reused, before having clear instructions from the manufacturer's company and following the American Food and Drug Administration FDA regulations and requirements or national regulations. Our study had confirmed that early diagnosis and prompt recall of suspected cases and applying outbreak control measures helped to achieve good visual and anatomic outcomes, although the causative agent was multidrug-resistant $P$. aeruginosa.

\section{Acknowledgements}

We would like to thank Dr. Nahed El Wazir, Medical director of RIO hospital and Dr. Manal H. Aboelela, Ass. Prof. of public health and Deputy director of RIO hospital for their help in accessing patients' files and other hospital medical data used in this article.

\section{Funding}

Not applicable.

\section{Availability of data and materials}

All data generated or analysed during this study are included in this published article.

\footnotetext{
Authors' contributions

AE made the main contributions to the work design, microbiological laboratory testing of eye samples, environmental samples collection and processing, data collection from patients' files, drafting the manuscript, and revising and approving the final version. She was responsible for submission of the article as a corresponding author and performance of necessary revision and correction to the manuscript. SN has been involved in the microbiological laboratory testing of eye samples and recording of results, data collection, and revising and approving the final manuscript content. Al performed the clinical work of the study including patient examination and assessment, operative sample collection, treatment prescription and followup, and final recording of patient's clinical condition. He wrote the clinical aspect of the study, revised the manuscript, and gave final approval for publishing. MA shared performance of the clinical aspect of the work including patients recall, examination, and clinical assessments before and after treatment schedule, sample collection and follow-up, and recording of patient's clinical condition. He read the manuscript and gave his final approval to be published.
}

\section{Ethics approval and consent to participate}

The work had been approved ethically and had the agreement of the Medical Research Committee of the Research Institute of Ophthalmology
RIO, Egypt, prior to the beginning of the study. Eye samples used in the study for pathogen isolation and culture and sensitivity were obtained after patients consent as part of the treatment plan.

\section{Consent for publication}

Not applicable (participants were fully anonymous).

\section{Competing interests}

The authors declare that they have no competing interests.

\section{Publisher's Note}

Springer Nature remains neutral with regard to jurisdictional claims in published maps and institutional affiliations.

\section{Author details}

${ }^{1}$ Microbiology and Immunology Unit, Department of Microbiology and Parasitology, Research Institute of Ophthalmology (RIO), 2 El Ahram Street, Giza 12611, Egypt. '2Department of Microbiology and Parasitology, Research Institute of Ophthalmology, Giza, Egypt. ${ }^{3}$ Department of Ophthalmology, Research Institute of Ophthalmology, Giza, Egypt.

Received: 14 November 2018 Accepted: 17 January 2019

Published online: 28 January 2019

\section{References}

Arsan AK, Adișen A, Duman S, Aslan B (1996) Acute endophthalmitis outbreak after cataract surgery. J Cataract Refract Surg 22:1116-1120

Bispo PJ, Haas W, Gilmore MS (2015) Biofilms in infections of the eye. Pathogens 4:111-136. https://doi.org/10.3390/pathogens4010111

Boks T, Van Dissel JT, Teterissa N, Ros F (2006) An outbreak of endophthalmitis after extracapsular cataract surgery probably caused by endotoxin contaminated distilled water used to dissolve acetylcholine. Br J Ophthalmol 90:1094-1097

Centers for Disease Control and Prevention (CDC) (1996) Outbreaks of postoperative bacterial endophthalmitis caused by intrinsically contaminated ophthalmic solutions - Thailand, 1992 and Canada, 1993. MMWR Morb Mortal Weekly Rep 45:49-44

Chen KJ, Sun MH, Lai CC, Wu WC, Chen TL, Kuo YH (2011) Endophthalmitis caused by Pseudomonas aeruginosa in Taiwan. Retina 31:1193-1198

Cruciani M, Malena M, Amalfitano G, Monti P, Bonomi L (1998) Molecular epidemiology in a cluster of cases of postoperative Pseudomonas aeruginosa endophthalmitis. Clin Infect Dis 26:330-333

Durand ML (2017) Bacterial and fungal endophthalmitis. Clin Microbiol Rev 30(3): $597-613$

Eifrig CW, Scott IU, Flynn HW, Miller D (2003) Endophthalmitis caused by Pseudomonas aeruginosa. Ophthalmology 110:1714-1717

Endophthalmitis Vitrectomy Study Group EVSG (1995) Results of the endophthalmitis vitrectomy study. A randomized trial of immediate vitrectomy and intravenous antibiotics for the treatment of postoperative bacterial endophthalmitis. Arch Ophthalmol 113:1479-1496 Available from; https://www.ncbi.nlm.nih.gov/pubmed/7487614

Falavarjani KG, Alemzadeh SA, Habibi A, Hadavandkhani A, Askari S \& Pourhabibi A (2017). Pseudomonas aeruginosa Endophthalmitis: Clinical Outcomes and Antibiotic Susceptibilities. Ocular Immunology and Inflammation Journal, 25: 377-381. https://doi.org/10.3109/09273948.2015.1132740.

Gad GF, El-Domany RA, Zaki S, Ashour HMJ (2007) Characterization of Pseudomonas aeruginosa isolated from clinical and environmental samples in Minia, Egypt: prevalence, antibiogram and resistance mechanisms. Antimicrob Chemother 60:1010-1017

Graybill-D'Ercole P (2013) Implementing AORN Recommended Practices for Sterilization. AORN Journal 97 (5):521-533.

Grohmann P (2018) Medicines and healthcare products regulatory agency MHRA single-use medical devices: implications and consequences of reuse v2.2. Medicines and Healthcare Products Regulatory Agency, British Standards, London, pp 2-14

Guerra RL, Freitas Bde P, Parcero CM, Maia Ode O Jr, Marback RL (2012) An outbreak of forty five cases of Pseudomonas aeruginosa acute endophthalmitis after phacoemulsification. Arq BrasOftalmol 75:344-347

Hoffmann KK, Weber DJ, Gergen MF, Rutala WA, Talte G (2002) Pseudomonas aeruginosa-related postoperative endophthalmitis linked to a contaminated phacoemulsifier. Arch Ophthalmol 120:90-93 
Hudzicki J, Kirby-Bauer Disk Diffusion Susceptibility Test rotocol. American Society for Microbiology ASM, Microbe Library. Created December 2009, last update April 2013. https://www.asm.org/Protocols/Kirby-Bauer-Disk-DiffusionSusceptibility-Test-Pro

Kenchappa P, Sangwan VS, Ahmed N, Rao KR, Pathengay A (2009) Highresolution genotyping of Pseudomonas aeruginosa strains linked to acute post cataract surgery endophthalmitis outbreaks in India. Ann Clin Microbiol Antimicrob 4:19

Kresloff MS, Castellarin AA, Zarbin MA (1998) Endophthalmitis. Surv Ophthalmol 43:193-224

Kuznar W (2017) High level of antibiotic resistance in endophthalmitis. MedPage Today November 14, Available from; https://www.medpagetoday.com/ meetingcoverage/aao/69266

Mahran M, Mohssen M, Negm S, Shafikk M (2014) Multivariate analysis of microbial keratitis in Egypt. World Appl Sci J 32:2421-2430

Mateos I, Valencia R, Torres MJ, Cantos A, Conde M, Aznar J (2006) Nosocomial outbreak of Pseudomonas aeruginosa endophthalmitis. Infect Control Hosp Epidemiol 27:1249-1251

Pathengay A, Flynn HW Jr, Isom RF, Miller D (2012) Endophthalmitis outbreaks following cataract surgery: causative organisms, etiologies and visual acuity outcomes. J Cataract Refract Surg 38:1278-1282

Pijl BJ, Theelen T, Tilanus MAD, Rentenaar R, Crama N (2010) Acute endophthalmitis after cataract surgery: 250 consecutive cases treated at a tertiary referral center in the Netherlands. Am J Ophthalmol 149(3):482-487

Pinna A, Usai D, Sechi LA, Zanetti S, Jesudasan NC, Thomas PA, Kaliamurthy J (2010) An outbreak of post-cataract surgery endophthalmitis caused by Pseudomonas aeruginosa. Ophthalmology 116:2321-2326 Ophthalmology. 117: 1657-8; author reply 1658-9

Ramappa M, Majii AB, Murthy SI, Balne PK, Nalamada S, Garudadri C, Mathai A, Gopinathan U, Garg P (2015) An outbreak of acute post-cataract surgery Pseudomonas sp. endophthalmitis caused by contaminated hydrophilic intraocular lens solution. Pathogens 23(4):111-136

Saeed S, Rasheed H (2011) Evaluation of bacterial contamination of Pakistani paper currency notes (rupee) in circulation in Karachi; European. J Biol Sci 3. 94-98

Schmier JK, Hulme-Lowe CK, Covert DW, Lau EC (2016) An updated estimate of costs of endophthalmitis following cataract surgery among Medicare patients: 2010-2014. Clin Ophthalmol 10:2121-2127

Sebrell C (2009) Statement from the Academy and American society of cataract and refractive surgery ASCRS regarding the joint commission's clarification of its position on sterilization practices; recommendations for ophthalmic surgery centers: Reviewed: September 2013 Release 15 June 2009, pp 1095-1100

Sunenshine R, Schultz M, Lawrence MG, Shin S, Jensen B, Zubairi S, Labriola AM (2009a) An outbreak of postoperative gram-negative bacterial Endophthalmitis associated with contaminated trypan blue ophthalmic solution. Clin Infect Dis 48(11):1580-1583

Sunenshine R, Schultz M, Lawrence MG, Shin S, Jensen B, Zubairi S, Labriola AM Shams A, Noble-Wang J, Matthew J, Arduino M (2009b) An outbreak of postoperative gram-negative bacterial endophthalmitis associated with contaminated trypan blue ophthalmic solution. Clin Infect Dis 48(11):15801583 http://cid.oxfordjournals.org/content/48/11.toc

Swaddiwudhipong W, Tangkitchot T, Silarug N (1995) An outbreak of Pseudomonas aeruginosa postoperative endophthalmitis caused by contaminated intraocular irrigating solution. Trans R Soc Trop Med Hyg 89:288

Wayne Pa, Performance standards for antimicrobial disk susceptibility test, 2006. 16 informational supplement, M100-S16. Vol.26: CLSI, pp: 1-178

Yoshizumi MO, Bhavsar AR, Dessouki A, Kashani A (1999) Safety of repeated intravitreous injections of antibiotics and dexamethasone. Retina 19:437-441

Zaluski S, Clayman HM, Karsenti G, Bourzeix S, Tournemire A (1999) Pseudomonas aeruginosa endophthalmitis caused by contamination of the internal fluid pathways of a phacoemulsifier. J Cataract Refract Surg 25:540-545

\section{Submit your manuscript to a SpringerOpen ${ }^{\circ}$ journal and benefit from:}

- Convenient online submission

- Rigorous peer review

- Open access: articles freely available online

- High visibility within the field

- Retaining the copyright to your article

Submit your next manuscript at $\boldsymbol{\nabla}$ springeropen.com 